\title{
Strong convergence theorems for generalized nonexpansive mappings on star-shaped set with applications
}

Eskandar Naraghirad' and Lai-Jiu Lin ${ }^{2 *}$

\section{"Correspondence:}

maljlin@cc.ncue.edu.tw

${ }^{2}$ Department of Mathematics,

National Changhua University of

Education, Changhua, 50058,

Taiwan

Full list of author information is

available at the end of the article

\begin{abstract}
In this paper, we study attractive points for a class of generalized nonexpansive mappings on star-shaped sets and establish strong convergence theorems of the Halpern iterative sequences generated by these mappings in a real Hilbert space. We modify Halpern's iterations for finding an attractive point of a mapping $T$ satisfying condition (E) on a star-shaped set $\mathrm{C}$ in a real Hilbert space $\mathrm{H}$ and provide an affirmative answer to an open problem posed by Akashi and Takahashi in a recent work of (Appl. Math. Comput. 219(4):2035-2040, 2012) for nonexpansive and nonspreading mappings. Furthermore, we study the approximation of common attractive points of generalized nonexpansive mappings and derive a strong convergence theorem by a new iteration scheme for these mappings. As applications of our results, we study multiple sets split monotone inclusion problems for inverse strongly monotone mappings, multiple sets split optimization problems, and multiple sets split feasibility problems. Our results contain many original results on multiple sets split feasibility problem in the literature. Our results also improve and generalize many well-known results in the current literature.

MSC: $47 \mathrm{H} 10 ; 37 \mathrm{C} 25$
\end{abstract}

Keywords: nonspreading mapping; generalized nonexpansive mapping; fixed point; attractive point; multiple sets split monotone variational inclusion problem; multiple sets split optimization problem; multiple sets split feasibility problem

\section{Introduction}

Throughout this paper, we denote the set of real numbers and the set of positive integers by $\mathbb{R}$ and $\mathbb{N}$, respectively. Let $H$ be a Hilbert space with the norm $\|\cdot\|$ and $C$ a nonempty subset of $H$. Let $T: C \rightarrow H$ be a mapping. We denote by $F(T)$ the set of fixed points of $T$ and by $A(T)$ the set of attractive points (see [1]) of $T$, i.e.,

$$
F(T)=\{x \in C: T x=x\} \quad \text { and } \quad A(T)=\{x \in H:\|T y-x\| \leq\|y-x\|, \forall y \in C\} .
$$

A mapping $T: C \rightarrow H$ is said to be nonexpansive if $\|T x-T y\| \leq\|x-y\|$ for all $x, y \in C$. A mapping $T: C \rightarrow H$ is said to be quasi-nonexpansive if $F(T) \neq \emptyset$ and $\|T x-y\| \leq\|x-y\|$ for all $x \in C$ and $y \in F(T)$. A mapping $T: C \rightarrow H$ is said to be strongly monotone if there exists $\bar{\gamma}>0$ such that $\langle x-y, T x-T y\rangle \geq \bar{\gamma}\|x-y\|^{2}$ for all $x, y \in H$.

@2014 Naraghirad and Lin; licensee Springer. This is an Open Access article distributed under the terms of the Creative Commons Attribution License (http://creativecommons.org/licenses/by/2.0), which permits unrestricted use, distribution, and reproduction in any medium, provided the original work is properly cited. 
Recall that the one-step Halpern iteration (see [2]) is given by the following formula:

$$
x_{n+1}=\alpha_{n} u+\left(1-\alpha_{n}\right) T x_{n}, \quad u \in C, x_{1} \in C .
$$

Here, $\left\{\alpha_{n}\right\}_{n \in \mathbb{N}}$ is a real sequence in $[0,1]$ satisfying some appropriate conditions. A more general iteration scheme of one-step Halpern iteration is two-step Halpern iteration given by

$$
\left\{\begin{array}{l}
u \in C, x_{1} \in C \quad \text { chosen arbitrarily, } \\
y_{n}=\left(1-\beta_{n}\right) x_{n}+\beta_{n} T x_{n} \\
x_{n+1}=\alpha_{n} u+\left(1-\alpha_{n}\right) y_{n}
\end{array}\right.
$$

where the sequences $\left\{\beta_{n}\right\}_{n \in \mathbb{N}}$ and $\left\{\alpha_{n}\right\}_{n \in \mathbb{N}}$ satisfy some appropriate conditions. In particular, when all $\beta_{n}=1$, the Halpern iteration (1.2) becomes the standard Halpern iteration (1.2).

Definition 1.1 Let $C$ be a nonempty subset of a Hilbert space $H$. Then $C$ is called starshaped if there exists $z \in C$ such that for any $x \in C$ and any $\lambda \in(0,1)$,

$$
\lambda z+(1-\lambda) x \in C .
$$

Such $z \in C$ is called a center of the star-shaped set $C$.

Recently, Takahashi and Takeuchi [1] introduced the concept of attractive points. Akashi and Takahashi [3] proved the following strongly convergence attractive point theorem for nonexpansive mappings on a star-shaped set $C$ of a Hilbert space.

Theorem 1.1 Let $H$ be a Hilbert space and $C$ be a star-shaped subset of $H$ with center $z \in C$. Let $T: C \rightarrow C$ be a nonexpansive mapping with $A(T) \neq \emptyset$. Suppose that $\left\{x_{n}\right\}_{n \in \mathbb{N}}$ is a sequence generated by $x_{1}=x \in C$ and

$$
x_{n+1}=\alpha_{n} z+\left(1-\alpha_{n}\right) T x_{n}, \quad \forall n \in \mathbb{N},
$$

where $0 \leq \alpha_{n} \leq 1, \lim _{n \rightarrow \infty} \alpha_{n}=0, \sum_{n=1}^{\infty} \alpha_{n}=\infty$ and $\sum_{n=1}^{\infty}\left|\alpha_{n}-\alpha_{n+1}\right|<\infty$. Then $\left\{x_{n}\right\}_{n \in \mathbb{N}}$ converges strongly to $P_{A(T)} z$, where $P_{A(T)}$ is metric projection of $H$ onto $A(T)$.

Akashi and Takahashi [3] posed the following open problem in their final remark.

Question 1.1 Is there any strong convergence theorem of Halpern's type for a wide class of nonlinear mappings which contains nonexpansive mappings and nonspreading mappings in a real Hilbert space $H$ ?

Definition 1.2 ([4]) Let $C$ be a nonempty subset of a Banach space $X$. For $\mu \geq 1$, we say that a mapping $T: C \rightarrow X$ satisfies condition $\left(\mathrm{E}_{\mu}\right)$ on $C$ if there exists $\mu \geq 1$ such that for all $x, y \in C$,

$$
\|x-T y\| \leq \mu\|x-T x\|+\|x-y\| .
$$

We say that $T$ satisfies condition (E) on $C$ whenever $T$ satisfies $\left(\mathrm{E}_{\mu}\right)$ on $C$ for some $\mu \geq 1$. 
The split feasibility problem (SFP) is to find a point

$$
x^{*} \in C \text { such that } A x^{*} \in Q \text {, }
$$

where $C$ is a nonempty closed convex subset of a Hilbert space $H_{1}, Q$ is a nonempty closed convex subset of a Hilbert space $H_{2}$, and $A: H_{1} \rightarrow H_{2}$ is an operator. The split feasibility problem in finite dimensional Hilbert spaces was first introduced by Censor et al. [5] for modeling inverse problems which arise from phase retrievals and in medical image reconstruction. The split feasibility problem has applications in signal processing, image reconstruction, approximation theory, control theory, biomedical engineering, communications, and geophysics. One may refer to [6-9].

Let $C_{1}, C_{2}, \ldots, C_{m}$ be nonempty closed convex subsets of a Hilbert space $H_{1}$, let $Q_{1}, Q_{2}, \ldots, Q_{n}$ be nonempty, closed convex subsets of Hilbert space $H_{2}$ and let $A_{1}, A_{2}$, $\ldots, A_{m}: H_{1} \rightarrow H_{2}$ be linear operators. The well known multiple sets split feasibility problem (MSSFP) is to find $x^{*} \in H_{1}$ such that $x^{*} \in C_{i}$ and $A_{i} x^{*} \in Q_{i}$ for all $i=1,2, \ldots, m$.

Multiple sets split feasibility problem (MSSFP) contains convex feasibility problem (CFP) and split feasibility problems (SFP) as special cases $[5,10,11]$.

In this paper, we study attractive points for a class of generalized nonexpansive mappings on star-shaped sets and establish strong convergence theorems of the Halpern iterative sequences generated by these mappings in a real Hilbert space. We modify the Halpern iterations for finding an attractive point of a mapping $T$ satisfying condition (E) on a star-shaped set $C$ in a real Hilbert space $H$ and provide an affirmative answer to open Question 1.1. Furthermore, we study the approximation of common attractive points of generalized nonexpansive mappings and derive a strong convergence theorem by a new iterative scheme for these mappings. As applications of our results, we study multiple sets split monotone inclusion problems for inverse strongly monotone mappings, multiple sets split optimization problem, multiple sets split feasibility problem. To the best of our knowledge, there is no result on multiple sets split monotone inclusion for inverse strongly monotone mappings and multiple sets split optimization problem in the literature. Our results also improve and generalize many well-known results in the current literature; see, for example, [3].

\section{Preliminaries}

Following Kohsaka and Takahashi [12], a mapping $T: C \rightarrow H$ is said to be nonspreading if

$$
2\|T x-T y\|^{2} \leq\|T x-y\|^{2}+\|x-T y\|^{2}
$$

for all $x, y \in C$.

Let $C$ be a nonempty, closed convex subset of a Hilbert space $H$ and $x \in H$. Then there exists a unique nearest point $z \in C$ such that $\|x-z\|=\inf _{y \in C}\|x-y\|$. We denote such a correspondence by $z=P_{C} x$. The mapping $P_{C}$ is called a metric projection of $H$ onto $C$.

Definition 2.1 ([13]) Let $C$ be a nonempty subset of a Banach space $X$. We say that a mapping $T: C \rightarrow X$ satisfies condition (C) on $C$ if for all $x, y \in C$,

$$
\frac{1}{2}\|x-T x\| \leq\|x-y\|
$$


implies

$$
\|T x-T y\| \leq\|x-y\| .
$$

Remark 2.1 ([13] and [4]) Let $T: C \rightarrow X$.

(i) It is obvious that if $T$ is nonexpansive, then $T$ satisfies $\left(\mathrm{E}_{\mu}\right)$ on $C$ for some $\mu \geq 1$, but the converse is not true.

(ii) If $T$ satisfies condition (C), then $T$ satisfies $\left(\mathrm{E}_{\mu}\right)$ on $C$ for some $\mu \geq 1$, but the converse is not true.

(iii) If $T$ satisfies condition (E), it is easy to see that

$$
A(T) \cap C=F(T) .
$$

In this section, we collect some lemmas which will be used in the proofs for the main results in next sections. We start with the following well-known lemma.

Lemma 2.1 ([14]) Let $H$ be a real Hilbert space and $C$ a nonempty convex subset of $H$. For given $x \in H$ :

(i) $z=P_{C} x$ if and only if

$$
\langle x-z, y-z\rangle \leq 0, \quad \forall y \in C .
$$

(ii) $z=P_{C} x$ if and only if

$$
\|x-z\|^{2} \leq\|x-y\|^{2}-\|y-z\|^{2}, \quad \forall y \in C .
$$

(iii) $\left\langle P_{C} x-P_{C} y, x-y\right\rangle \geq\left\|P_{C} x-P_{C} y\right\|^{2}, \forall x, y \in H$. Consequently, $P_{C}$ is a nonexpansive mapping.

Lemma 2.2 ([15]) In a Hilbert space $H$, we have

(i) for all $x, y \in H$ and $\lambda \in[0,1]$

$$
\|\lambda x+(1-\lambda) y\|^{2}=\lambda\|x\|^{2}+(1-\lambda)\|y\|^{2}-\lambda(1-\lambda)\|x-y\|^{2} ;
$$

(ii) for all $x, y, z \in H$

$$
\|x-y\|^{2} \leq\|x-(y+z)\|^{2}+2\langle x-y, z\rangle
$$

(iii) for all $x, y \in H$

$$
\|x+y\|^{2} \leq\|x\|^{2}+2\langle y, x+y\rangle
$$

(iv) for all $x, y, w \in H$,

$$
\langle(x-y)+(x-w), y-w\rangle=\|x-w\|^{2}-\|x-y\|^{2} .
$$


Takahashi and Takeuchi [1] proved the following useful lemmas related to attractive points of a nonempty set $C$ in a Hilbert space $H$.

Lemma 2.3 Let $C$ be a nonempty subset of a real Hilbert space $H$ and $T: C \rightarrow H$ be a mapping. Then $A(T)$ is a closed convex subset of $H$.

Lemma 2.4 Let $C$ be a nonempty subset of a real Hilbert space $H$ and $T: C \rightarrow H$ be a mapping. If $\left\{u_{n}\right\}_{n \in \mathbb{N}}$ be a sequence in $H$ such that

$$
\limsup _{n \rightarrow \infty}\left\{\left(u_{n}-y\right)+\left(u_{n}-T y\right), y-T y\right\rangle \leq 0
$$

for all $y \in C$. If a subsequence $\left\{u_{n_{i}}\right\}_{i \in \mathbb{N}}$ of $\left\{u_{n}\right\}_{n \in \mathbb{N}}$, converges weakly to $u \in H$, then $u \in A(T)$.

Lemma 2.5 Let $C$ be a nonempty subset of a real Hilbert space $H$ and $T: C \rightarrow C$ be a nonexpansive mapping. Then the following assertions are equivalent.

(1) The attractive point set $A(T) \neq \emptyset$.

(2) There exists $x \in C$ such that the sequence $\left\{T^{n} x\right\}_{n \in \mathbb{N}}$ is bounded.

Proposition 2.1 Let $C$ be a nonempty subset of a Banach space $X$ and $T: C \rightarrow C$ be a mapping which satisfies condition $\left(\mathrm{E}_{\mu}\right)$ for some $\mu \geq 1$. Then the following statements hold.

(i) For all $x \in C$,

$$
\left\|x-T^{2} x\right\| \leq(\mu+1)\|x-T x\| .
$$

(ii) For all $x, y \in C$,

$$
\|T x-T y\| \leq \mu(\mu+2)\|x-T x\|+\|T x-y\|
$$

(iii) For all $x, y \in C$,

$$
\|T x-T y\|^{2}-\|T x-y\|^{2} \leq\left[\mu^{2}(\mu+2)^{2}\|x-T x\|^{2}+2 \mu(\mu+2)\|T x-y\|\right]\|x-T x\| .
$$

Proof

(i) Since $T$ satisfies condition $\left(\mathrm{E}_{\mu}\right)$,

$$
\left\|x-T^{2} x\right\| \leq \mu\|x-T x\|+\|x-T x\| \leq(\mu+1)\|x-T x\| .
$$

(ii) By (i),

$$
\begin{aligned}
\|T x-T y\| & \leq \mu\left\|T x-T^{2} x\right\|+\|T x-y\| \\
& \leq \mu\left(\|T x-x\|+\left\|x-T^{2} x\right\|\right)+\|T x-y\| \\
& \leq \mu(\mu+2)\|T x-x\|+\|T x-y\| .
\end{aligned}
$$

(iii) This follows immediately from (ii). This completes the proof. 
Example 2.1 Let $T:[0,2] \rightarrow[0,2]$ be defined by

$$
T x= \begin{cases}0 & \text { if } x \in[0,2), \\ 1 & \text { if } x=2\end{cases}
$$

Then $T$ is a nonspreading mapping with $F(T)=\{0\}$. Indeed, for any $x \in[0,2)$ and $y=2$, we have $T x=0$ and $T y=1$. Observe now that

$$
\begin{aligned}
2|T x-T y|^{2} & =2|0-1|^{2} \\
& \leq|x-1|^{2}+|2-0|^{2} \\
& =|x-T y|^{2}+|y-T x|^{2} .
\end{aligned}
$$

The other cases can be verified similarly. It is worth mentioning that $T$ is neither nonexpansive nor continuous.

Proposition 2.2 Let $C$ be a nonempty subset of a Banach space $X$ and $T: C \rightarrow C$ be a mapping. If $T$ is a nonspreading mapping, then it satisfies condition $\left(\mathrm{E}_{2}\right)$ on $C$.

Proof Since $T$ is a nonspreading mapping, then we have

$$
2\|T x-T y\|^{2} \leq\|T x-y\|^{2}+\|x-T y\|^{2}, \quad \forall x, y \in C .
$$

This implies that, for any $x, y \in C$,

$$
\text { (1) }\|T x-T y\| \leq\|T x-y\| \quad \text { or } \quad(2)\|T x-T y\| \leq\|x-T y\| .
$$

If (1) holds, then we have

$$
\begin{aligned}
\|x-T y\| & \leq\|x-T x\|+\|T x-T y\| \\
& \leq\|x-T x\|+\|T x-y\| \\
& \leq\|x-T x\|+\|T x-x\|+\|x-y\| \\
& =2\|x-T x\|+\|x-y\| .
\end{aligned}
$$

If (2) holds, then we obtain

$$
\begin{aligned}
\|y-T x\| & \leq\|y-T y\|+\|T y-T x\| \\
& \leq\|y-T y\|+\|x-T y\| \\
& \leq\|y-T y\|+\|x-y\|+\|y-T y\| \\
& =2\|y-T y\|+\|x-y\| .
\end{aligned}
$$

This completes the proof.

Let us give an example of a generalized nonexpansive mapping which is not a nonspreading mapping. 
Example 2.2 Let $T:[-2,1] \rightarrow[-2,1]$ be defined by

$$
T x= \begin{cases}\frac{|x|}{2} & \text { if } x \in[-2,1), \\ -\frac{1}{2} & \text { if } x=1 .\end{cases}
$$

It could easily be verified that $T$ satisfies condition (E) on [-2,1]; for more details, see [4]. However, the mapping $T$ is not a nonspreading mapping. Indeed, for $x=-2$ and $y=1$, we have $T x=1$ and $T y=-\frac{1}{2}$. Thus we obtain

$$
2|T x-T y|^{2}=2\left|1+\frac{1}{2}\right|^{2}=\frac{9}{2}
$$

and

$$
|T x-y|^{2}+|x-T y|^{2}=\left|-2+\frac{1}{2}\right|^{2}=\frac{9}{4} .
$$

If $T$ is a nonspreading mapping, then, in view of (2.2), we have

$$
|T x-T y|^{2}=\frac{9}{2} \leq \frac{9}{4}
$$

This is a contradiction. Therefore, $T$ is not a nonspreading mapping.

Lemma 2.6 (see [16, Lemma 2.1]) Let $\left\{s_{n}\right\}_{n \in \mathbb{N}}$ be a sequence of nonnegative real numbers satisfying the inequality:

$$
s_{n+1} \leq\left(1-\gamma_{n}\right) s_{n}+\gamma_{n} \delta_{n}, \quad \forall n \geq 0
$$

where $\left\{\gamma_{n}\right\}_{n \in \mathbb{N}}$ and $\left\{\delta_{n}\right\}_{n \in \mathbb{N}}$ satisfy the conditions:

(i) $\left\{\gamma_{n}\right\}_{n \in \mathbb{N}} \subset[0,1]$ and $\sum_{n=0}^{\infty} \gamma_{n}=\infty$, or equivalently, $\prod_{n=0}^{\infty}\left(1-\gamma_{n}\right)=0$;

(ii) $\lim \sup _{n \rightarrow \infty} \delta_{n} \leq 0$, or

(ii) $^{\prime} \sum_{n=0}^{\infty} \gamma_{n} \delta_{n}<\infty$.

Then $\lim _{n \rightarrow \infty} s_{n}=0$.

To prove our main result, we need the following lemma.

Lemma 2.7 ([17]) Let $\left\{s_{n}\right\}_{n \in \mathbb{N}}$ be a sequence of nonnegative real numbers, let $\left\{\alpha_{n}\right\}_{n \in \mathbb{N}}$ be a sequence of $[0,1]$ with $\sum_{n=1}^{\infty} \alpha_{n}=\infty$, let $\left\{\beta_{n}\right\}_{n \in \mathbb{N}}$ be a sequence of nonnegative real numbers with $\sum_{n=1}^{\infty} \beta_{n}<\infty$ and let $\left\{\gamma_{n}\right\}_{n \in \mathbb{N}}$ be a sequence of real numbers with $\lim _{\sup _{n \rightarrow \infty}} \gamma_{n} \leq 0$. Suppose that

$$
s_{n+1} \leq\left(1-\alpha_{n}\right) s_{n}+\alpha_{n} \gamma_{n}+\beta_{n}, \quad \forall n \geq 0 .
$$

Then $\lim _{n \rightarrow \infty} s_{n}=0$.

The following lemma has been proved in [18]. 
Lemma 2.8 Let $\left\{a_{n}\right\}_{n \in \mathbb{N}}$ be a sequence of real numbers such that there exists a subsequence $\left\{n_{i}\right\}_{i \in \mathbb{N}}$ of $\{n\}_{n \in \mathbb{N}}$ such that $a_{n_{i}}<a_{n_{i}+1}$ for all $i \in \mathbb{N}$. Then there exists a subsequence $\left\{m_{k}\right\}_{k \in \mathbb{N}} \subset \mathbb{N}$ such that $m_{k} \rightarrow \infty$ and the following properties are satisfied by all (sufficiently large) numbers $k \in \mathbb{N}$ :

$$
a_{m_{k}} \leq a_{m_{k}+1} \text { and } a_{k} \leq a_{m_{k}+1}
$$

In fact, $m_{k}=\max \left\{j \leq k: a_{j}<a_{j+1}\right\}$.

Let $X$ be a real Banach space. The modulus $\delta$ of convexity of $X$ is denoted by

$$
\delta(\epsilon)=\inf \left\{1-\frac{\|x+y\|}{2}:\|x\| \leq 1,\|y\| \leq 1,\|x-y\| \geq \epsilon\right\}
$$

for every $\epsilon$ with $0 \leq \epsilon \leq 2$. A Banach space $X$ is said to be uniformly convex if $\delta(\epsilon)>0$ for every $\epsilon>0$. It is well that any Hilbert space is a uniformly convex Banach space; see, for more details [14].

We know the following result from [19].

Lemma 2.9 Let $X$ be a uniformly convex Banach space and $B_{r}:=\{x \in X:\|x\| \leq r\}, r>0$. Then there exists a continuous strictly increasing convex function $g:[0, \infty) \rightarrow[0, \infty)$ with $g(0)=0$ such that

$$
\|\lambda x+\beta y+\gamma z\|^{2} \leq \lambda\|x\|^{2}+\beta\|y\|^{2}+\gamma\|z\|^{2}-\lambda \beta g(\|x-y\|)
$$

for all $x, y, z \in B_{r}$ and all $\lambda, \beta, \gamma \in[0,1]$ with $\lambda+\beta+\gamma=1$.

The following result has been proved in [20].

Lemma 2.10 Let $X$ be a uniformly convex Banach space, $r>0$ be a constant. Then there exists a continuous, strictly increasing and convex function $g:[0, \infty) \rightarrow[0, \infty)$ such that

$$
\left\|\sum_{k=0}^{\infty} \alpha_{k} x_{k}\right\|^{2} \leq \sum_{k=0}^{\infty} \alpha_{k}\left\|x_{k}\right\|^{2}-\alpha_{i} \alpha_{j} g\left(\left\|x_{i}-x_{j}\right\|\right)
$$

for all $i, j \in \mathbb{N} \cup\{0\}, x_{k} \in B_{r}:=\{z \in X:\|z\| \leq r\}, \alpha_{k} \in(0,1)$ and $k \in \mathbb{N} \cup\{0\}$ with $\sum_{k=0}^{\infty} \alpha_{k}=1$.

\section{Strong convergence theorems}

The following result presents an existence theorem of attractive points of a generalized nonexpansive mapping $T$ on a nonempty subset $C$ of a Hilbert space $H$.

Theorem 3.1 Let $C$ be a nonempty subset of a real Hilbert space $H$. Let $T: C \rightarrow C$ be a mapping satisfying condition (E) on $C$ which is uniformly asymptotically regular, i.e., $\lim _{n \rightarrow \infty}\left\|T^{n} x-T^{n+1} x\right\|=0$ for all $x \in C$. Then the following assertions are equivalent.

(1) The attractive point set $A(T) \neq \emptyset$.

(2) There exists $x \in C$ such that the sequence $\left\{T^{n} x\right\}_{n \in \mathbb{N}}$ is bounded. 
Proof The implication (1) $\Longrightarrow(2)$ is obvious. For the converse implication, suppose that there exists $x \in C$ such that the sequence $\left\{T^{n} x\right\}_{n \in \mathbb{N}}$ is bounded. Setting $u_{n}=T^{n} x$ for all $n \in \mathbb{N}$, the uniformly asymptotically regularity of $T$ assures that

$$
\lim _{n \rightarrow \infty}\left\|T u_{n}-u_{n}\right\|=\lim _{n \rightarrow \infty}\left\|T^{n+1} x-T^{n} x\right\|=0 .
$$

Since $\left\{u_{n}\right\}_{n \in \mathbb{N}}$ is bounded and $C$ is a nonempty subset of the Hilbert space $H$, there exists a subsequence $\left\{u_{n_{k}}\right\}_{k \in \mathbb{N}}$ of $\left\{u_{n}\right\}_{n \in \mathbb{N}}$ such that $u_{n_{k}} \rightarrow y \in C$ as $k \rightarrow \infty$. Next, we denote $u_{n_{k}}$ by $x_{k}$ for all $k \in \mathbb{N}$. This, together with (3.1), implies that

$$
\lim _{k \rightarrow \infty}\left\|T x_{k}-x_{k}\right\|=\lim _{k \rightarrow \infty}\left\|T u_{n_{k}}-u_{n_{k}}\right\|=0 \quad \text { and } \quad x_{k}-y \quad \text { as } k \rightarrow \infty .
$$

Thus we have

$$
\limsup _{k \rightarrow \infty}\left\|x_{k}-T y\right\| \leq \mu \limsup _{k \rightarrow \infty}\left\|T x_{k}-x_{k}\right\|+\limsup _{k \rightarrow \infty}\left\|x_{k}-y\right\|=\limsup _{k \rightarrow \infty}\left\|x_{k}-y\right\| .
$$

The Opial property implies that $y \in F(T) \subset A(T)$, which completes the proof.

The following strong convergence result provides an affirmative answer to open Question 1.1 in the case where the mapping $T$ is a generalized nonexpansive mapping.

Theorem 3.2 Let $H$ be a Hilbert space and $C$ be a star-shaped subset of $H$ with center $z \in C$. Let $T: C \rightarrow C$ be a mapping satisfying condition (E) on $C$ such that $A(T) \neq \emptyset$. Suppose that $\left\{x_{n}\right\}_{n \in \mathbb{N}}$ is a sequence generated by $x_{1}=x \in C$ and

$$
x_{n+1}=\alpha_{n} z+\left(1-\alpha_{n}\right) T x_{n}, \quad \forall n \in \mathbb{N},
$$

where $0 \leq \alpha_{n} \leq 1, \lim _{n \rightarrow \infty} \alpha_{n}=0, \sum_{n=1}^{\infty} \alpha_{n}=\infty$ and $\sum_{n=1}^{\infty}\left|\alpha_{n}-\alpha_{n+1}\right|<\infty$. Then $\left\{x_{n}\right\}_{n \in \mathbb{N}}$ converges strongly to $P_{A(T)} z$, where $P_{A(T)}$ is metric projection of $H$ onto $A(T)$.

Proof Let $x_{1} \in C$ and $u=P_{A(T)} z$. Following the same argument as in Theorem 3.1 [3], we can show that the sequences $\left\{x_{n}\right\}_{n \in \mathbb{N}}$ and $\left\{T x_{n}\right\}_{n \in \mathbb{N}}$ are bounded.

Let $K:=\sup \left\{\left|\|z\|,\left\|T x_{n}-u\right\|\right|: n \in \mathbb{N}\right\}$, with the same argument as in Theorem 3.1 [3], we see that

$$
\left\|x_{n+1}-x_{n}\right\| \leq 2 K\left|\alpha_{n}-\alpha_{n+1}\right|+\left(1-\alpha_{n}\right)\left\|x_{n}-x_{n-1}\right\| .
$$

Since $0 \leq \alpha_{n} \leq 1, \lim _{n \rightarrow \infty} \alpha_{n}=0, \sum_{n=1}^{\infty} \alpha_{n}=\infty$ and $\sum_{n=1}^{\infty}\left|\alpha_{n}-\alpha_{n+1}\right|<\infty$, we have from Lemma 2.7 that

$$
\lim _{n \rightarrow \infty}\left\|x_{n+1}-x_{n}\right\|=0
$$

This last result together with (3.2) amounts to

$$
\lim _{n \rightarrow \infty}\left\|x_{n}-T x_{n}\right\|=0
$$


In view of Lemma 2.2(iv), we get, for any $y \in C$,

$$
\begin{aligned}
& \limsup _{n \rightarrow \infty}\left\{\left(x_{n}-y\right)+\left(x_{n}-T y\right), y-T y\right\rangle \\
& \quad=\limsup _{n \rightarrow \infty}\left\langle\left(T x_{n}-y\right)+\left(T x_{n}-T y\right), y-T y\right\rangle \\
& \quad=\limsup _{n \rightarrow \infty}\left(\left\|T x_{n}-T y\right\|^{2}-\left\|T x_{n}-y\right\|^{2}\right) \\
& \quad \leq \limsup _{n \rightarrow \infty}\left[\mu^{2}(\mu+2)^{2}\left\|x_{n}-T x_{n}\right\|^{2}+2 \mu(\mu+2)\left\|T x_{n}-y\right\|\right]\left\|x_{n}-T x_{n}\right\| \\
& \quad \leq \limsup _{n \rightarrow \infty}\left[\mu^{2}(\mu+2)^{2}+2 \mu(\mu+2)\right] M_{1}\left\|x_{n}-T x_{n}\right\|,
\end{aligned}
$$

where $M_{1}=\sup \left\{\left\|T x_{n}-y\right\|,\left\|T x_{n}-x_{n}\right\|: n \in \mathbb{N}\right\}$. Thus we obtain

$$
\limsup _{n \rightarrow \infty}\left\langle\left(x_{n}-y\right)+\left(x_{n}-T y\right), y-T y\right\rangle \leq 0, \quad \forall y \in C
$$

Since $\left\{x_{n}\right\}_{n \in \mathbb{N}}$ is bounded, there exists a subsequence $\left\{x_{n_{i}}\right\}_{i \in \mathbb{N}}$ of $\left\{x_{n}\right\}_{n \in \mathbb{N}}$ such that $x_{n_{i}} \rightarrow y$, and

$$
\limsup _{n \rightarrow \infty}\left\langle x_{n}-u, z-u\right\rangle=\lim _{i \rightarrow \infty}\left\langle x_{n_{i}}-u, z-u\right\rangle=\langle y-u, z-u\rangle
$$

By Lemma 2.4, $y \in A(T)$. This, together with Lemma 2.1(ii), implies that

$$
\begin{aligned}
\limsup _{n \rightarrow \infty}\left\langle x_{n+1}-u, z-u\right\rangle \leq & \limsup _{n \rightarrow \infty}\left\langle x_{n+1}-x_{n}, z-u\right\rangle \\
& +\limsup _{n \rightarrow \infty}\left\langle x_{n}-u, z-u\right\rangle \\
= & \limsup _{n \rightarrow \infty}\left\langle x_{n}-u, z-u\right\rangle \\
= & \lim _{i \rightarrow \infty}\left\langle x_{n_{i}}-u, z-u\right\rangle \\
= & \langle y-u, z-u\rangle=\left\langle y-P_{A(T)} z, z-P_{A(T)} z\right\rangle \\
\leq & 0 .
\end{aligned}
$$

From Lemma 2.2(iii) and (3.2), we have

$$
\begin{aligned}
\left\|x_{n+1}-P_{A(T)} z\right\|^{2} & =\left\|\alpha_{n} z+\left(1-\alpha_{n}\right) x_{n}-P_{A(T)} z\right\|^{2} \\
& \leq\left\|\left(1-\alpha_{n}\right)\left(x_{n}-P_{A(T)} z\right)\right\|^{2}+2 \alpha_{n}\left\langle x_{n+1}-P_{A(T)} z, z-P_{A(T)} z\right\rangle \\
& \leq\left(1-\alpha_{n}\right)\left\|x_{n}-P_{A(T)} z\right\|^{2}+2 \alpha_{n}\left\langle x_{n+1}-P_{A(T)} z, z-P_{A(T)} z\right\rangle
\end{aligned}
$$

Then Theorem 3.2 follows from Lemma 2.7.

Applying Theorems 3.1 and 3.2 and following the same arguments as Theorem 3.2 [3], we have the following fixed point theorem, which generalizes Theorem 3.2 [3]. 
Theorem 3.3 Let H be a Hilbert space and C be a closed star-shaped subset of H. Let T: $C \rightarrow C$ be a mapping satisfying condition (E) on $C$ such that $T$ is uniformly asymptotically regular and $\left\{T^{n} x\right\}_{n \in \mathbb{N}}$ is bounded for some $x \in C$. Then $F(T) \neq \emptyset$.

For the special case of Theorem 3.2, we have the following fixed point theorem.

Corollary 3.1 Let H be a Hilbert space and C be a closed star-shaped subset of H. Let T : $C \rightarrow C$ be a mapping satisfying condition (C) on $C$ such that $T$ is uniformly asymptotically regular and $\left\{T^{n} x\right\}_{n \in \mathbb{N}}$ is bounded for some $x \in C$. Then $F(T) \neq \emptyset$.

Applying Theorem 3.2 and following the same arguments as Theorem 3.4 [3], we have the following fixed point convergence theorem, which generalizes Theorem 3.4 [3].

Theorem 3.4 Let $H$ be a Hilbert space and $C$ be a closed star-shaped subset of $H$ with center $z \in C$. Let $T: C \rightarrow C$ be a mapping satisfying condition $(\mathrm{E})$ on $C$ such that $F(T) \neq \emptyset$. Suppose that $\left\{x_{n}\right\}_{n \in \mathbb{N}}$ is a sequence generated by $x_{1}=x \in C$ and

$$
x_{n+1}=\alpha_{n} z+\left(1-\alpha_{n}\right) T x_{n}, \quad \forall n \in \mathbb{N},
$$

where $0 \leq \alpha_{n} \leq 1, \lim _{n \rightarrow \infty} \alpha_{n}=0, \sum_{n=1}^{\infty} \alpha_{n}=\infty$ and $\sum_{n=1}^{\infty}\left|\alpha_{n}-\alpha_{n+1}\right|<\infty$. Then $\left\{x_{n}\right\}_{n \in \mathbb{N}}$ converges strongly to some $u_{0} \in F(T)$, where

$$
u_{0}=\arg \min _{u \in F(T)}\|u-z\|
$$

Corollary 3.2 Let $H$ be a Hilbert space and $C$ be a closed star-shaped subset of $H$ with center $z \in C$. Let $T: C \rightarrow C$ be a mapping satisfying condition $(C)$ on $C$ such that $F(T) \neq \emptyset$. Suppose that $\left\{x_{n}\right\}_{n \in \mathbb{N}}$ is a sequence generated by $x_{1}=x \in C$ and

$$
x_{n+1}=\alpha_{n} z+\left(1-\alpha_{n}\right) T x_{n}, \quad \forall n \in \mathbb{N},
$$

where $0 \leq \alpha_{n} \leq 1, \lim _{n \rightarrow \infty} \alpha_{n}=0, \sum_{n=1}^{\infty} \alpha_{n}=\infty$ and $\sum_{n=1}^{\infty}\left|\alpha_{n}-\alpha_{n+1}\right|<\infty$. Then $\left\{x_{n}\right\}_{n \in \mathbb{N}}$ converges strongly to some $u_{0} \in F(T)$, where

$$
u_{0}=\arg \min _{u \in F(T)}\|u-z\|
$$

Remark 3.1 The two-step Halpern iteration process is a generalization of the one-step Halpern iteration process. It provides more flexibility in defining the algorithm parameters which is important from the numerical implementation perspective.

In the following, we prove strong convergence theorems of common attractive points for generalized nonexpansive mappings in a Hilbert space.

Theorem 3.5 Let $H$ be a Hilbert space and $C$ be a convex subset of $H$ and $z \in C$. Let $T_{1}: C \rightarrow C$ be a mapping satisfying condition $\left(\mathrm{E}_{\lambda}\right)$ on $C$ and $T_{2}: C \rightarrow C$ be a mapping satisfying condition $\left(\mathrm{E}_{\mu}\right)$ on $C$ such that $A:=A\left(T_{1}\right) \cap A\left(T_{2}\right) \neq \emptyset$. Let $\left\{\alpha_{n}\right\}_{n \in \mathbb{N}},\left\{\beta_{n, 1}\right\}_{n \in \mathbb{N}}$, $\left\{\beta_{n, 2}\right\}_{n \in \mathbb{N}}$, and $\left\{\beta_{n, 3}\right\}_{n \in \mathbb{N}}$ be sequences in $[0,1]$ satisfying the following control conditions: 
(a) $\lim _{n \rightarrow \infty} \alpha_{n}=0$;

(b) $\sum_{n=1}^{\infty} \alpha_{n}=\infty$;

(c) $\beta_{n, 1}+\beta_{n, 2}+\beta_{n, 3}=1, \forall n \in \mathbb{N}$;

(d) $\liminf _{n \rightarrow \infty} \beta_{n, j} \beta_{n, 3}>0, j=1,2$.

Let $\left\{x_{n}\right\}_{n \in \mathbb{N}}$ be a sequence generated by

$$
\left\{\begin{array}{l}
x_{1} \in C \quad \text { chosen arbitrarily, } \\
y_{n}=\beta_{n, 1} T_{1} x_{n}+\beta_{n, 2} T_{2} x_{n}+\beta_{n, 3} x_{n} \\
x_{n+1}=\alpha_{n} z+\left(1-\alpha_{n}\right) y_{n} .
\end{array}\right.
$$

Then the sequence $\left\{x_{n}\right\}_{n \in \mathbb{N}}$ defined in (3.3) converges strongly to $P_{A} z$, where $P_{A}$ is the metric projection from $H$ onto $A$.

Proof We divide the proof into several steps. Set

$$
u=P_{A} z
$$

Step 1. We prove that the sequences $\left\{x_{n}\right\}_{n \in \mathbb{N}},\left\{y_{n}\right\}_{n \in \mathbb{N}},\left\{T_{1} x_{n}\right\}_{n \in \mathbb{N}}$, and $\left\{T_{2} x_{n}\right\}_{n \in \mathbb{N}}$ are bounded.

We first show that $\left\{x_{n}\right\}_{n \in \mathbb{N}}$ is bounded.

Let $p \in A$ be fixed. In view of Lemma 2.9 , there exists a continuous strictly increasing convex function $g:[0, \infty) \rightarrow[0, \infty)$ with $g(0)=0$ such that

$$
\begin{aligned}
\left\|y_{n}-p\right\|^{2}= & \left\|\beta_{n, 1} T_{1} x_{n}+\beta_{n, 2} T_{2} x_{n}+\beta_{n, 3} x_{n}-p\right\|^{2} \\
\leq & \beta_{n, 1}\left\|T_{1} x_{n}-p\right\|^{2}+\beta_{n, 2}\left\|T_{2} x_{n}-p\right\|^{2}+\beta_{n, 3}\left\|x_{n}-p\right\|^{2} \\
& \quad-\beta_{n, j} \beta_{n, 3} g\left(\left\|x_{n}-T_{j} x_{n}\right\|\right) \\
\leq & \beta_{n, 1}\left\|x_{n}-p\right\|^{2}+\beta_{n, 2}\left\|x_{n}-p\right\|^{2}+\beta_{n, 3}\left\|x_{n}-p\right\|^{2} \\
& \quad-\beta_{n, j} \beta_{n, 3} g\left(\left\|x_{n}-T_{j} x_{n}\right\|\right) \\
= & \left\|x_{n}-p\right\|^{2}-\beta_{n, j} \beta_{n, 3} g\left(\left\|x_{n}-T_{j} x_{n}\right\|\right) \\
\leq & \left\|x_{n}-p\right\|^{2}, \quad j=1,2 .
\end{aligned}
$$

This together with (3.3) entails

$$
\begin{aligned}
\left\|x_{n+1}-p\right\| & =\left\|\alpha_{n} u+\left(1-\alpha_{n}\right) y_{n}-p\right\| \\
& \leq \alpha_{n}\|u-p\|+\left(1-\alpha_{n}\right)\left\|y_{n}-p\right\| \\
& \leq \alpha_{n}\|u-p\|+\left(1-\alpha_{n}\right)\left\|x_{n}-p\right\| \\
& \leq \max \left\{\|u-p\|,\left\|x_{n}-p\right\|\right\} .
\end{aligned}
$$

Consequently, by induction, we deduce that

$$
\left\|x_{n+1}-p\right\| \leq \max \left\{\|u-p\|,\left\|x_{1}-p\right\|\right\}
$$

for all $n \in \mathbb{N}$. This implies that the sequence $\left\{\left\|x_{n}-p\right\|\right\}_{n \in \mathbb{N}}$ is bounded and hence the sequence $\left\{x_{n}\right\}_{n \in \mathbb{N}}$ is bounded. Then, by (3.4), $\left\{y_{n}\right\}_{n \in \mathbb{N}},\left\{T_{1} x_{n}\right\}_{n \in \mathbb{N}}$, and $\left\{T_{2} x_{n}\right\}_{n \in \mathbb{N}}$ are bounded. 
Step 2. We prove that for any $n \in \mathbb{N}$

$$
\left\|x_{n+1}-u\right\|^{2} \leq\left(1-\alpha_{n}\right)\left\|x_{n}-u\right\|^{2}+2 \alpha_{n}\left\langle x_{n+1}-u, z-u\right\rangle .
$$

Let us show (3.5). For each $n \in \mathbb{N}$ and $j=1,2$, in view of (3.4), we obtain

$$
\left\|y_{n}-u\right\|^{2} \leq\left\|x_{n}-u\right\|^{2}-\beta_{n, j} \beta_{n, 3} g\left(\left\|x_{n}-T_{j} x_{n}\right\|\right) .
$$

This implies that

$$
\begin{aligned}
\left\|x_{n+1}-u\right\|^{2} & =\left\|\alpha_{n} z+\left(1-\alpha_{n}\right) y_{n}-u\right\|^{2} \\
& \leq \alpha_{n}\|z-u\|^{2}+\left(1-\alpha_{n}\right)\left\|y_{n}-u\right\|^{2} \\
& \leq \alpha_{n}\|z-u\|^{2}+\left(1-\alpha_{n}\right)\left[\left\|x_{n}-u\right\|^{2}-\beta_{n, j} \beta_{n, 3} g\left(\left\|x_{n}-T_{j} x_{n}\right\|\right)\right] .
\end{aligned}
$$

Let $M_{2}:=\sup \left\{\left|\|z-u\|^{2}-\left\|x_{n}-u\right\|^{2}\right|: n \in \mathbb{N}, j=1,2\right\}$. It follows from (3.6) that

$$
\beta_{n, j} \beta_{n, 3} g\left(\left\|x_{n}-T_{j} x_{n}\right\|\right) \leq\left\|x_{n}-u\right\|^{2}-\left\|x_{n+1}-u\right\|^{2}+\alpha_{n} M_{2}, \quad j=1,2 .
$$

In view of Lemma 2.2(ii) and (3.4), we obtain

$$
\begin{aligned}
\left\|x_{n+1}-u\right\|^{2} & =\left\|\alpha_{n} z+\left(1-\alpha_{n}\right) y_{n}-u\right\|^{2} \\
& \leq\left\|\alpha_{n} z+\left(1-\alpha_{n}\right) y_{n}-u-\alpha_{n}(z-u)\right\|^{2}+2\left\langle x_{n+1}-u, \alpha_{n}(z-u)\right\rangle \\
& =\left\|\left(1-\alpha_{n}\right)\left(y_{n}-u\right)\right\|^{2}+2 \alpha_{n}\left\langle x_{n+1}-u, z-u\right\rangle \\
& \leq\left(1-\alpha_{n}\right)\left\|y_{n}-u\right\|^{2}+2 \alpha_{n}\left\langle x_{n+1}-u, z-u\right\rangle \\
& \leq\left(1-\alpha_{n}\right)\left\|x_{n}-u\right\|^{2}+2 \alpha_{n}\left\langle x_{n+1}-u, z-u\right\rangle .
\end{aligned}
$$

Step 3. We prove that $x_{n} \rightarrow u$ as $n \rightarrow \infty$.

We discuss the following two possible cases.

Case 1. Suppose that there exists $n_{0} \in \mathbb{N}$ such that $\left\{\left\|x_{n}-u\right\|\right\}_{n=n_{0}}^{\infty}$ is nonincreasing. Then the sequence $\left\{\left\|x_{n}-u\right\|\right\}_{n \in \mathbb{N}}$ is convergent. Thus we have $\left\|x_{n}-u\right\|^{2}-\left\|x_{n+1}-u\right\|^{2} \rightarrow 0$ as $n \rightarrow \infty$. This, together with conditions (c), (d), and (3.7), imply that

$$
\lim _{n \rightarrow \infty}\left\|x_{n}-T_{1} x_{n}\right\|=0, \quad \text { and } \quad \lim _{n \rightarrow \infty}\left\|x_{n}-T_{2} x_{n}\right\|=0 .
$$

On the other hand, we have

$$
y_{n}-x_{n}=\beta_{n, 1}\left(x_{n}-T_{1} x_{n}\right)+\beta_{n, 2}\left(x_{n}-T_{2} x_{n}\right), \quad \text { and } \quad x_{n+1}-y_{n}=\alpha_{n}\left(z-y_{n}\right) .
$$

This implies that

$$
\lim _{n \rightarrow \infty}\left\|y_{n}-x_{n}\right\|=0, \quad \text { and } \quad \lim _{n \rightarrow \infty}\left\|x_{n+1}-y_{n}\right\|=0 .
$$

By the triangle inequality, we conclude that

$$
\left\|x_{n+1}-x_{n}\right\| \leq\left\|x_{n+1}-y_{n}\right\|+\left\|y_{n}-x_{n}\right\| .
$$


It follows from (3.9) that

$$
\lim _{n \rightarrow \infty}\left\|x_{n+1}-x_{n}\right\|=0
$$

Using Proposition 2.1, Lemma 2.2(iv), and (3.8), we obtain for any $y \in C$

$$
\begin{aligned}
& \limsup _{n \rightarrow \infty}\left\langle\left(x_{n}-y\right)+\left(x_{n}-T_{2} y\right), y-T_{2} y\right\rangle \\
& \quad=\limsup _{n \rightarrow \infty}\left\langle\left(T_{2} x_{n}-y\right)+\left(T_{2} x_{n}-T_{2} y\right), y-T_{2} y\right\rangle \\
& \quad=\limsup _{n \rightarrow \infty}\left(\left\|T_{2} x_{n}-T_{2} y\right\|^{2}-\left\|T_{2} x_{n}-y\right\|^{2}\right) \\
& \quad \leq \limsup _{n \rightarrow \infty}\left[\mu^{2}(\mu+2)^{2}\left\|x_{n}-T_{2} x_{n}\right\|^{2}+2 \mu(\mu+2)\left\|T_{2} x_{n}-y\right\|\right]\left\|x_{n}-T_{2} x_{n}\right\| \\
& \quad \leq \limsup _{n \rightarrow \infty}\left[\mu^{2}(\mu+2)^{2}+2 \mu(\mu+2)\right] M_{3}\left\|x_{n}-T_{2} x_{n}\right\|,
\end{aligned}
$$

where $M_{3}=\sup \left\{\left\|T_{2} x_{n}-y\right\|,\left\|T_{2} x_{n}-x_{n}\right\|: n \in \mathbb{N}\right\}$. Thus we obtain

$$
\limsup _{n \rightarrow \infty}\left\{\left(x_{n}-y\right)+\left(x_{n}-T_{2} y\right), y-T_{2} y\right\rangle \leq 0, \quad \forall y \in C
$$

Similarly, we have

$$
\begin{aligned}
& \limsup _{n \rightarrow \infty}\left\langle\left(x_{n}-y\right)+\left(x_{n}-T_{1} y\right), y-T_{1} y\right\rangle \\
& \quad=\limsup _{n \rightarrow \infty}\left\{\left(T_{1} x_{n}-y\right)+\left(T_{1} x_{n}-T_{1} y\right), y-T_{1} y\right\rangle \\
& \quad=\limsup _{n \rightarrow \infty}\left(\left\|T_{1} x_{n}-T_{1} y\right\|^{2}-\left\|T_{1} x_{n}-y\right\|^{2}\right) \\
& \quad \leq \limsup _{n \rightarrow \infty}\left[\lambda^{2}(\lambda+2)^{2}+2 \lambda(\lambda+2)\right] M_{4}\left\|x_{n}-T_{1} x_{n}\right\|,
\end{aligned}
$$

where $M_{4}=\sup \left\{\left\|T_{1} x_{n}-y\right\|,\left\|T_{1} x_{n}-x_{n}\right\|: n \in \mathbb{N}\right\}$.

Thus we obtain

$$
\limsup _{n \rightarrow \infty}\left\{\left(x_{n}-y\right)+\left(x_{n}-T_{1} y\right), y-T_{1} y\right\rangle \leq 0, \quad \forall y \in C
$$

Since $\left\{x_{n}\right\}_{n \in \mathbb{N}}$ is bounded, there exists a subsequence $\left\{x_{n_{i}}\right\}_{i \in \mathbb{N}}$ of $\left\{x_{n}\right\}_{n \in \mathbb{N}}$ such that $x_{n_{i}} \rightarrow y$, and

$$
\limsup _{n \rightarrow \infty}\left\langle x_{n}-u, z-u\right\rangle=\lim _{i \rightarrow \infty}\left\langle x_{n_{i}}-u, z-u\right\rangle=\langle y-u, z-u\rangle
$$

By Lemma 2.4, (3.10), and (3.11), $y \in A\left(T_{1}\right) \cap A\left(T_{2}\right)$. By Lemma 2.1(ii), we show that

$$
\begin{aligned}
\limsup _{n \rightarrow \infty}\left\langle x_{n+1}-u, z-u\right\rangle \leq & \limsup _{n \rightarrow \infty}\left\langle x_{n+1}-x_{n}, z-u\right\rangle \\
& +\limsup _{n \rightarrow \infty}\left\langle x_{n}-u, z-u\right\rangle \\
= & \limsup _{n \rightarrow \infty}\left\langle x_{n}-u, z-u\right\rangle
\end{aligned}
$$




$$
\begin{aligned}
& =\lim _{i \rightarrow \infty}\left\langle x_{n_{i}}-u, z-u\right\rangle \\
& =\langle y-u, z-u\rangle=\left\langle y-P_{A} z, z-P_{A} z\right\rangle \\
& \leq 0 .
\end{aligned}
$$

Thus we have the desired result by (3.5) and Lemma 2.6.

Case 2. Suppose that there exists a subsequence $\left\{n_{i}\right\}_{i \in \mathbb{N}}$ of $\{n\}_{n \in \mathbb{N}}$ such that

$$
\left\|x_{n_{i}}-u\right\|<\left\|x_{n_{i}+1}-u\right\|
$$

for all $i \in \mathbb{N}$. Then, by Lemma 2.8 , there exists a nondecreasing sequence $\left\{m_{k}\right\}_{k \in \mathbb{N}} \subset \mathbb{N}$ such that $m_{k} \rightarrow \infty$,

$$
\left\|u-x_{m_{k}}\right\| \leq\left\|u-x_{m_{k}+1}\right\| \quad \text { and } \quad\left\|u-x_{k}\right\| \leq\left\|u-x_{m_{k}+1}\right\|
$$

for all $k \in \mathbb{N}$. This, together with (3.7), imply that

$$
\beta_{m_{k}}\left(1-\beta_{m_{k}}\right)\left\|x_{m_{k}}-T_{j} x_{m_{k}}\right\|^{2} \leq\left\|x_{m_{k}}-u\right\|^{2}-\left\|x_{m_{k}+1}-u\right\|^{2}+\alpha_{m_{k}} M_{2} \leq \alpha_{m_{k}} M_{2}
$$

for all $k \in \mathbb{N}$ and $j=1,2$. By conditions (a), (c), and (d), we have

$$
\lim _{k \rightarrow \infty}\left\|x_{m_{k}}-T_{j} x_{m_{k}}\right\|=0, \quad j=1,2
$$

By the same argument, as in Case 1, we arrive at

$$
\limsup _{k \rightarrow \infty}\left\langle x_{m_{k}+1}-u, z-u\right\rangle \leq 0
$$

It follows from (3.7) that

$$
\left\|x_{m_{k}+1}-u\right\|^{2} \leq\left(1-\alpha_{m_{k}}\right)\left\|x_{m_{k}}-u\right\|^{2}+2 \alpha_{m_{k}}\left\langle x_{m_{k}+1}-u, z-u\right\rangle .
$$

Since $\left\|x_{m_{k}}-u\right\| \leq\left\|x_{m_{k}+1}-u\right\|$, we have

$$
\begin{aligned}
\alpha_{m_{k}}\left\|x_{m_{k}}-u\right\|^{2} & \leq\left\|x_{m_{k}}-u\right\|^{2}-\left\|x_{m_{k}+1}-u\right\|^{2}+2 \alpha_{m_{k}}\left\langle x_{m_{k}+1}-u, z-u\right\rangle \\
& \leq 2 \alpha_{m_{k}}\left\langle x_{m_{k}+1}-u, z-u\right\rangle
\end{aligned}
$$

In particular, since $\alpha_{m_{k}}>0$, we obtain

$$
\left\|x_{m_{k}}-u\right\|^{2} \leq 2\left\langle x_{m_{k}+1}-u, z-u\right\rangle
$$

In view of (3.15), we deduce that

$$
\lim _{k \rightarrow \infty}\left\|x_{m_{k}}-u\right\|=0
$$

This, together with (3.14), implies that

$$
\lim _{k \rightarrow \infty}\left\|x_{m_{k}+1}-u\right\|=0
$$


On the other hand, we have $\left\|x_{k}-u\right\| \leq\left\|x_{m_{k}+1}-u\right\|$ for all $k \in \mathbb{N}$ which implies that $x_{k} \rightarrow u$ as $k \rightarrow \infty$. Thus, we have $x_{n} \rightarrow u$ as $n \rightarrow \infty$. We thus complete the proof.

Corollary 3.3 Let $H$ be a Hilbert space and $C$ be a convex subset of $H$ and $z \in C$. Let $T: C \rightarrow C$ a mapping satisfying condition (E) on C such that $A(T) \neq \emptyset$. Let $\left\{\alpha_{n}\right\}_{n \in \mathbb{N}}$ and $\left\{\beta_{n}\right\}_{n \in \mathbb{N}}$ be two sequences in $[0,1]$ satisfying the following control conditions:

(a) $\lim _{n \rightarrow \infty} \alpha_{n}=0$;

(b) $\sum_{n=1}^{\infty} \alpha_{n}=\infty$;

(c) $\liminf _{n \rightarrow \infty} \beta_{n}\left(1-\beta_{n}\right)>0$.

Let $\left\{x_{n}\right\}_{n \in \mathbb{N}}$ be a sequence generated by

$$
\left\{\begin{array}{l}
x_{1} \in C \quad \text { chosen arbitrarily, } \\
y_{n}=\left(1-\beta_{n}\right) x_{n}+\beta_{n} T x_{n}, \\
x_{n+1}=\alpha_{n} z+\left(1-\alpha_{n}\right) y_{n} .
\end{array}\right.
$$

Then the sequence $\left\{x_{n}\right\}_{n \in \mathbb{N}}$ defined in (3.16) converges strongly to $P_{A(T)} z$, where $P_{A(T)}$ is the metric projection from $H$ onto $A(T)$.

Applying Theorem 3.5, we study the approximation of common fixed points of generalized nonexpansive mappings and derive a strong convergence theorem by a new iteration scheme for these mappings.

Theorem 3.6 Let $H$ be a Hilbert space and $C$ be a closed convex subset of $H$ and $z \in C$. Let $T_{1}: C \rightarrow C$ be a mapping satisfying condition $\left(\mathrm{E}_{\lambda}\right)$ on $C$ and $T_{2}: C \rightarrow C$ a mapping satisfying condition $\left(\mathrm{E}_{\mu}\right)$ on $C$ such that $F:=F\left(T_{1}\right) \cap F\left(T_{2}\right) \neq \emptyset$. Let $\left\{\alpha_{n}\right\}_{n \in \mathbb{N}},\left\{\beta_{n, 1}\right\}_{n \in \mathbb{N}},\left\{\beta_{n, 2}\right\}_{n \in \mathbb{N}}$, $\left\{\beta_{n, 3}\right\}_{n \in \mathbb{N}}$ be sequences in $[0,1]$ satisfying the following control conditions:

(a) $\lim _{n \rightarrow \infty} \alpha_{n}=0$;

(b) $\sum_{n=1}^{\infty} \alpha_{n}=\infty$;

(c) $\beta_{n, 1}+\beta_{n, 2}+\beta_{n, 3}=1, \forall n \in \mathbb{N}$;

(d) $\liminf _{n \rightarrow \infty} \beta_{n, j} \beta_{n, 3}>0, j=1,2$.

Let $\left\{x_{n}\right\}_{n \in \mathbb{N}}$ be a sequence generated by

$$
\left\{\begin{array}{l}
x_{1} \in C \quad \text { chosen arbitrarily, } \\
y_{n}=\beta_{n, 1} T_{1} x_{n}+\beta_{n, 2} T_{2} x_{n}+\beta_{n, 3} x_{n}, \\
x_{n+1}=\alpha_{n} z+\left(1-\alpha_{n}\right) y_{n} .
\end{array}\right.
$$

Then the sequence $\left\{x_{n}\right\}_{n \in \mathbb{N}}$ defined in (3.17) converges strongly to some $u_{0} \in F$, where

$$
u_{0}=\arg \min _{u \in F}\|u-z\|
$$

Proof Since $T_{1}$ and $T_{2}$ are mappings satisfying condition (E), for any $x \in C$ and $u \in F$, we have

$$
\left\|T_{1} x-u\right\| \leq\|u-x\|
$$

and

$$
\left\|T_{1} x-u\right\| \leq\|u-x\|
$$


This implies that $F \subseteq A\left(T_{1}\right) \cap A\left(T_{2}\right)$. Thus we obtain $A:=A\left(T_{1}\right) \cap A\left(T_{2}\right) \neq \emptyset$. It follows from Theorem 3.6, that $\left\{x_{n}\right\}_{n \in \mathbb{N}}$ converges strongly to $u_{0} \in A$. Since $C$ is closed, we have $u_{0} \in C$. We follow the same argument as in the proof of Theorem 3.3 [3], we can prove Theorem 3.7.

Using Lemma 2.10 and Theorem 3.5, we can prove the following result.

Theorem 3.7 Let $H$ be a Hilbert space and $C$ be a convex subset of $H$ and $z \in C$. For any $j \in \mathbb{N}$, let $T_{j}: C \rightarrow C$ be a mapping satisfying condition $\left(\mathrm{E}_{\lambda_{j}}\right)$ on $C$ such that $A:=$ $\bigcap_{j=1}^{\infty} A\left(T_{j}\right) \neq \emptyset$. Let $\left\{\alpha_{n}\right\}_{n \in \mathbb{N}},\left\{\beta_{n, j}\right\}_{n \in \mathbb{N}, j \in \mathbb{N} \cup\{0\}}$ be sequences in $[0,1]$ satisfying the following control conditions:

(a) $\lim _{n \rightarrow \infty} \alpha_{n}=0$;

(b) $\sum_{n=1}^{\infty} \alpha_{n}=\infty$;

(c) $\sum_{j=1}^{\infty} \beta_{n, j}+\beta_{n, 0}=1, \forall n \in \mathbb{N}$;

(d) $\liminf _{n \rightarrow \infty} \beta_{n, j} \beta_{n, 0}>0, \forall j \in \mathbb{N}$.

Let $\left\{x_{n}\right\}_{n \in \mathbb{N}}$ be a sequence generated by

$$
\left\{\begin{array}{l}
x_{1} \in C \text { chosen arbitrarily, } \\
y_{n}=\sum_{j=1}^{\infty} \beta_{n, j} T_{j} x_{n}+\beta_{n, 0} x_{n}, \\
x_{n+1}=\alpha_{n} z+\left(1-\alpha_{n}\right) y_{n} .
\end{array}\right.
$$

Then the sequence $\left\{x_{n}\right\}_{n \in \mathbb{N}}$ defined in (3.18) converges strongly to $P_{A} z$, where $P_{A}$ is the metric projection from $H$ onto $A$.

Remark 3.2 Theorem 3.7 improves Theorem 1.1 and many fixed point results in the literature.

\section{Applications to multiple sets split feasibility problems}

Let $\mathcal{H}_{1}$, and $\mathcal{H}_{2}$ be Hilbert spaces, $Q_{1}$, and $Q_{2}$ be nonempty, closed convex subsets of $\mathcal{H}_{1}$, and $\mathcal{H}_{2}$, respectively. Let $G: H_{1} \multimap H_{1}$ be a multivalued mapping. The effective domain of $G$ is denoted by $D(G)$, that is, $D(G)=\left\{x \in H_{1}: G x \neq \emptyset\right\}$. Then $G: H_{1} \multimap H_{1}$ is called

(i) a monotone operator on $Q_{1}$ if $\langle x-y, u-v\rangle \geq 0$ for all $x, y \in D(G), u \in G x$, and $v \in G y$;

(ii) a maximal monotone operator on $H_{1}$ if $G$ is a monotone operator on $H_{1}$ and its graph is not properly contained in the graph of any other monotone operator on $H_{1}$. A mapping $V: Q_{1} \rightarrow H_{1}$ is called $\alpha$-inverse strongly monotone on $Q_{1}$ (in short $\alpha$-ism), if

$$
\langle x-y, V x-V y\rangle \geq \alpha\|V x-V y\|^{2} \quad \text { for all } x, y \in Q_{1} \text { and } \alpha>0 .
$$

Let $I$ and $I_{2}$ denote the identity functions on $\mathcal{H}_{1}$, and $\mathcal{H}_{2}$, respectively. For each $i \in \mathbb{N}$, let

(i) $\kappa, \kappa_{i}$, and $\mu_{i}>0, B_{i}$ be a $\mu_{i}$-inverse strongly monotone mapping of $Q_{1}$ into $\mathcal{H}_{1}, L_{i}$ be a $\kappa_{i}$-inverse strongly monotone mapping of $Q_{2}$ into $H_{2}, L$ be a $\kappa$-inverse strongly monotone mapping of $Q_{2}$ into $H_{2}$;

(ii) $M$ and $M_{i}$ be maximal monotone mappings on $\mathcal{H}_{2}$ such that the domains of $M$ and $M_{i}$ are included in $Q_{2}, G_{i}$ be a maximal monotone mapping on $\mathcal{H}_{1}$ such that the domain of $G_{i}$ includes $Q_{1}$; 
(iii) $M_{i}^{-1} 0=\left\{x \in H_{i}: 0 \in M_{i} x\right\}, J_{\lambda_{n}}^{M_{i}}=\left(I+\lambda_{n} M_{i}\right)^{-1}, \lambda_{n}>0$;

(iv) $A: \mathcal{H}_{1} \rightarrow \mathcal{H}_{2}$ and $A_{i}: \mathcal{H}_{1} \rightarrow \mathcal{H}_{2}$ be bounded linear operators, $A$ and $A_{i}^{*}$ be the adjoints of $A$ and $A_{i}$, respectively;

(v) $R$ and $R_{i}$ be the spectral radii of $A^{*} A$ and $A_{i}^{*} A_{i}$, respectively.

Throughout this section, we use these notations and assumptions unless specified otherwise.

A mapping $T: H_{1} \rightarrow H_{1}$ is said to be averaged if $T=(1-\alpha) I+\alpha S$, where $\alpha \in(0,1)$ and $S: H_{1} \rightarrow H_{1}$ is nonexpansive. In this case, we also say that $T$ is $\alpha$-averaged. A firmly nonexpansive mapping is $\frac{1}{2}$-averaged.

Lemma 4.1 ([21, 22]) Let $C$ be a nonempty closed convex subset of a real Hilbert space $H$, and let $T: C \rightarrow C$ be a mapping. Then the following are satisfied:

(i) $T$ is nonexpansive if and only if the complement $(I-T)$ is a 1/2-ism.

(ii) If $S$ is $v$-ism, then for $\gamma>0, \gamma S$ is a $v / \gamma$-ism.

(iii) $S$ is averaged if and only if the complement $I-S$ is a $v$-ism for some $v>1 / 2$.

(iv) If $S$ and $T$ are both averaged, then the composite $S T$ of $S$ and $T$ is averaged.

(v) If the mappings $\left\{T_{i}\right\}_{i=1}^{n}$ are averaged and have a common fixed point, then $\bigcap_{i=1}^{n} \operatorname{Fix}\left(T_{i}\right)=\operatorname{Fix}\left(T_{1} \cdots T_{n}\right)$.

In order to study the convergence theorems for the solutions set of multiple sets split problems, we must give an essential result in this paper. We study the following essential problem (SFP-1):

Find $\bar{x} \in H_{1}$ such that $A \bar{x} \in(L+M)^{-1}(0)$.

Recently, Yu, Lin and Chuang [23] proved the following useful result.

Lemma 4.2 ([23]) Given any $\bar{x} \in H_{1}$, we have the following.

(i) If $\bar{x}$ is a solution of (SFP-1), then $\left(I-\lambda A^{*}\left(I_{2}-U\right) A\right) \bar{x}=\bar{x}$, where $\lambda>0$, $U=J_{\sigma}^{M}\left(I_{2}-\sigma L\right)$, and $\sigma>0$.

(ii) Suppose that $U=J_{\sigma}^{M}\left(I_{2}-\sigma L\right), 0<\lambda<\frac{1}{R}, 0<\sigma<2 \kappa$, then $J_{\sigma}^{M}\left(I_{2}-\sigma L\right)$, and $I-\lambda A^{*}\left(I_{2}-U\right) A$ are averaged. We assume further that the solution set of (SFP-1) is nonempty, and $\left(I-\lambda A^{*}\left(I_{2}-U\right) A\right) \bar{x}=\bar{x}$. Then $\bar{x}$ is a solution of (SFP-1).

In the following theorem, we study the following multiple sets variational inclusion problems (MSSVIP-1):

Find $\bar{x} \in \mathcal{H}_{1}$ such that $\bar{x} \in\left(G_{1}+B_{1}\right)^{-1} 0 \cap\left(G_{2}+B_{2}\right)^{-1} 0 \cap \cdots \cap\left(G_{m}+B_{m}\right)^{-1} 0$

and

$$
A_{1} \bar{x} \in\left(M_{1}+L_{1}\right)^{-1} 0, \quad A_{2} \bar{x} \in\left(M_{2}+L_{2}\right)^{-1} 0, \quad \ldots, \quad A_{l} \bar{x} \in\left(M_{l}+L_{l}\right)^{-1} 0,
$$

where $m \in \mathbb{N}$ and $l \in \mathbb{N}$.

Let $\Omega_{1}$ denote the solution set of the problem (MSSVIP-1). 
Theorem 4.1 Let $z \in \mathcal{H}_{1}$. Let $T_{1}: Q_{1} \rightarrow Q_{1}$ be a mapping defined by

$$
T_{1}=J_{\lambda_{1}}^{G_{1}}\left(I-\lambda_{1} B_{1}\right) J_{\lambda_{2}}^{G_{2}}\left(I-\lambda_{2} B_{2}\right) \cdots J_{\lambda_{m}}^{G_{m}}\left(I-\lambda_{m} B_{m}\right)
$$

and $T_{2}: Q_{1} \rightarrow Q_{1}$ be a mapping defined by

$$
T_{2}=\left(I-\sigma_{1} A_{1}^{*}\left(I_{2}-U_{1}\right) A_{1}\right)\left(I-\sigma_{2} A_{2}^{*}\left(I_{2}-U_{2}\right) A_{2}\right) \cdots\left(I-\sigma_{l} A_{l}^{*}\left(I_{2}-U_{l}\right) A_{l}\right),
$$

where $U_{i}=J_{\delta_{i}}^{M_{i}}\left(I_{2}-\delta_{i} L_{i}\right), m \in \mathbb{N}, i \in \mathbb{N}$ and $l \in \mathbb{N}$.

Suppose that $\Omega_{1} \neq \emptyset$.

Let $\left\{\alpha_{n}\right\}_{n \in \mathbb{N}},\left\{\beta_{n, 1}\right\}_{n \in \mathbb{N}},\left\{\beta_{n, 2}\right\}_{n \in \mathbb{N}},\left\{\beta_{n, 3}\right\}_{n \in \mathbb{N}}$ be sequences in $[0,1]$ satisfying the following control conditions:

(a) $\lim _{n \rightarrow \infty} \alpha_{n}=0$;

(b) $\sum_{n=1}^{\infty} \alpha_{n}=\infty$;

(c) $\beta_{n, 1}+\beta_{n, 2}+\beta_{n, 3}=1, \forall n \in \mathbb{N}$;

(d) $\liminf _{n \rightarrow \infty} \beta_{n, j} \beta_{n, 3}>0, j=1,2$;

(e) for each $i \in \mathbb{N}, 0<\delta_{i}<2 \kappa_{i}, 0<\lambda_{i}<2 \mu_{i}$, and $0<\sigma_{i}<\frac{1}{R_{i}}$.

Let $\left\{x_{n}\right\}_{n \in \mathbb{N}}$ be a sequence generated by

$$
\left\{\begin{array}{l}
x_{1} \in C \quad \text { chosen arbitrarily } \\
y_{n}=\beta_{n, 1} T_{1} x_{n}+\beta_{n, 2} T_{2} x_{n}+\beta_{n, 3} x_{n} \\
x_{n+1}=\alpha_{n} z+\left(1-\alpha_{n}\right) y_{n}
\end{array}\right.
$$

Then the sequence $\left\{x_{n}\right\}_{n \in \mathbb{N}}$ defined in (4.1) converges strongly to some $u_{0} \in \Omega_{1}$, where $u_{0}=$ $\arg \min _{u \in \Omega_{1}}\|u-z\|$.

Proof By Lemma 4.2, for each $i \in \mathbb{N}, J_{\lambda_{i}}^{G_{i}}\left(I-\lambda_{i} B_{i}\right)$ and $\left(I-\sigma_{i} A_{i}^{*}\left(I_{2}-U_{i}\right)\right)$ are averaged. Since $\Omega_{1} \neq \emptyset$, there exists $w \in \Omega_{1}$, such that

$$
w \in\left(G_{1}+B_{1}\right)^{-1} 0 \cap\left(G_{2}+B_{2}\right)^{-1} 0 \cap \cdots \cap\left(G_{m}+B_{m}\right)^{-1} 0
$$

and

$$
A_{1} w \in\left(M_{1}+L_{1}\right)^{-1} 0, \quad A_{2} w \in\left(M_{2}+L_{2}\right)^{-1} 0, \quad \ldots, \quad A_{l} w \in\left(M_{l}+L_{l}\right)^{-1} 0,
$$

$m \in \mathbb{N}$ and $l \in \mathbb{N}$.

By Lemma 4.2,

$$
w \in F\left(I-\sigma_{1} A_{1}^{*}\left(I_{2}-U_{1}\right) A_{1}\right) \cap F\left(I-\sigma_{2} A_{2}^{*}\left(I_{2}-U_{2}\right) A_{2}\right) \cap \cdots \cap F\left(I-\sigma_{l} A_{l}^{*}\left(I_{2}-U_{l}\right) A_{l}\right) .
$$

We also see that

$$
w \in F\left(J_{\lambda_{1}}^{G_{1}}\left(I-\lambda_{1} B_{1}\right)\right) \cap F\left(J_{\lambda_{2}}^{G_{2}}\left(I-\lambda_{2} B_{2}\right)\right) \cap \cdots \cap F\left(J_{\lambda_{m}}^{G_{m}}\left(I-\lambda_{m} B_{m}\right)\right) .
$$

By Lemma 4.1, we see that

$$
w \in F\left(J_{\lambda_{1}}^{G_{1}}\left(I-\lambda_{1} B_{1}\right)\right)\left(J_{\lambda_{2}}^{G_{2}}\left(I-\lambda_{2} B_{2}\right)\right) \cdots\left(J_{\lambda_{m}}^{G_{m}}\left(I-\lambda_{m} B_{m}\right)\right)
$$


and

$$
w \in F\left(I-\sigma_{1} A_{1}^{*}\left(I_{2}-U_{1}\right) A_{1}\right)\left(I-\sigma_{2} A_{2}^{*}\left(I_{2}-U_{2}\right) A_{2}\right) \cdots\left(I-\sigma_{l} A_{l}^{*}\left(I_{2}-U_{l}\right) A_{l}\right) .
$$

Therefore $w \in F:=F\left(T_{1}\right) \cap F\left(T_{2}\right)$ and $F \neq \emptyset$.

By Lemma 4.1 again, we see that $T_{1}$ and $T_{2}$ are averaged. Therefore $T_{1}$ and $T_{2}$ are nonexpansive mapping. Then by Theorem 3.7, the sequence $\left\{x_{n}\right\}_{n \in \mathbb{N}}$ defined in (4.1) converges strongly to some $u_{0} \in F$, where $u_{0}=\arg \min _{u \in F}\|u-z\|$. Since $\Omega_{1} \neq \emptyset$, it follows from Lemma 4.1 that $\Omega_{1}=F$. This completes the proof.

Remark 4.1 Moudafi [24] studied a weak convergence of split monotone variational inclusion problem, while Theorem 4.1 studied a strong convergence theorem for the multiple sets split monotone variational inclusion problem.

In the following theorem, we study the following multiple sets split inclusion problems for inverse strongly monotone mappings (MSSVIP-2):

Find $\bar{x} \in \mathcal{H}_{1}$ such that $\bar{x} \in B_{1}^{-1} 0 \cap B_{2}^{-1} 0 \cap \cdots \cap B_{m}^{-1} 0$

and

$$
A_{1} \bar{x} \in L_{1}^{-1} 0, \quad A_{2} \bar{x} \in L_{2}^{-1} 0, \quad \ldots, \quad A_{l} \bar{x} \in L_{l}^{-1} 0,
$$

where $m \in \mathbb{N}$ and $l \in \mathbb{N}$.

Let $\Omega_{2}$ denote the solution set of the problem (MSSVIP-2).

Theorem 4.2 Let $z \in \mathcal{H}_{1}$. Let $T_{1}: Q_{1} \rightarrow Q_{1}$ be a mapping defined by

$$
T_{1}=\left(I-\lambda_{1} B_{1}\right)\left(I-\lambda_{2} B_{2}\right) \cdots\left(I-\lambda_{m} B_{m}\right)
$$

and $T_{2}: Q_{1} \rightarrow Q_{1}$ be a mapping defined by

$$
T_{2}=\left(I-\sigma_{1} A_{1}^{*}\left(I_{2}-U_{1}\right) A_{1}\right)\left(I-\sigma_{2} A_{2}^{*}\left(I_{2}-U_{2}\right) A_{2}\right) \cdots\left(I-\sigma_{l} A_{l}^{*}\left(I_{2}-U_{l}\right) A_{l}\right),
$$

where $U_{i}=\left(I_{2}-\delta_{i} L_{i}\right), m \in \mathbb{N}, i \in \mathbb{N}$ and $l \in \mathbb{N}$.

Suppose that $\Omega_{2} \neq \emptyset$.

Let $\left\{\alpha_{n}\right\}_{n \in \mathbb{N}},\left\{\beta_{n, 1}\right\}_{n \in \mathbb{N}},\left\{\beta_{n, 2}\right\}_{n \in \mathbb{N}},\left\{\beta_{n, 3}\right\}_{n \in \mathbb{N}}$ be sequences in $[0,1]$ satisfying the following control conditions:

(a) $\lim _{n \rightarrow \infty} \alpha_{n}=0$;

(b) $\sum_{n=1}^{\infty} \alpha_{n}=\infty$;

(c) $\beta_{n, 1}+\beta_{n, 2}+\beta_{n, 3}=1, \forall n \in \mathbb{N}$;

(d) $\liminf _{n \rightarrow \infty} \beta_{n, j} \beta_{n, 3}>0, j=1,2$;

(e) for each $i \in \mathbb{N}, 0<\delta_{i}<2 \kappa_{i}, 0<\lambda_{i}<2 \mu_{i}$, and $0<\sigma_{i}<\frac{1}{R_{i}}$.

Let $\left\{x_{n}\right\}_{n \in \mathbb{N}}$ be a sequence generated by

$$
\left\{\begin{array}{l}
x_{1} \in C \quad \text { chosen arbitrarily, } \\
y_{n}=\beta_{n, 1} T_{1} x_{n}+\beta_{n, 2} T_{2} x_{n}+\beta_{n, 3} x_{n}, \\
x_{n+1}=\alpha_{n} z+\left(1-\alpha_{n}\right) y_{n} .
\end{array}\right.
$$


Then the sequence $\left\{x_{n}\right\}_{n \in \mathbb{N}}$ defined in (4.1) converges strongly to some $u_{0} \in \Omega_{2}$, where $u_{0}=$ $\arg \min _{u \in \Omega_{2}}\|u-z\|$.

Proof By Lemma 4.2, for each $i \in \mathbb{N},\left(I-\lambda_{i} B_{i}\right) U_{i}=\left(I_{2}-\delta_{i} L_{i}\right)$ are averaged and $I_{2}-U_{i}$ is $k_{i}$ inverse strongly monotone for some $k_{i} \geq \frac{1}{2}$. Following the same argument as in Theorem 3.1 [24], we can show that for each $i \in \mathbb{N}, A_{i}^{*}\left(I_{2}-U_{i}\right) A_{i}$, is $\frac{k_{i}}{R_{i}}$-inverse strong monotone. Following the same argument as in Theorem 4.1, we show that the sequence $\left\{x_{n}\right\}_{n \in \mathbb{N}}$ defined in (4.1) converges strongly to some $u_{0} \in F$, where $u_{0}=\arg \min _{u \in F}\|u-z\|$. Since $\Omega_{2} \neq \emptyset$, it follows from Lemma 4.1, it is easy to show that $\Omega_{2}=F$. This completes the proof of Theorem 4.2.

Remark 4.2 To the best of our knowledge, there are many results on inclusion problems for maximum monotone mappings, but there are no results on inclusion problem for inverse strongly monotone mappings or split inclusion problems for inverse strongly monotone mappings.

As an application of the split inclusion problem for inverse strongly monotone mappings, we study the following split optimization problem.

Let $V_{1}$ and $V_{2}$ be nonempty open convex sets in $\mathcal{H}_{1}$ and $\mathcal{H}_{2}$, respectively, $Q_{1} \subset V_{1}$, $Q_{2} \subset V_{2}$. For each $i \in \mathbb{N}$, let $f_{i}: V_{1} \rightarrow \mathcal{R}$ and $g_{i}: V_{2} \rightarrow \mathcal{R}$ be convex Gâteaux differential functions. In the following theorem, we study the following multiple sets split optimization problem (MSSVIP-3):

Find $\bar{x} \in \mathcal{Q}_{1}$ such that $\bar{x} \in \arg \min _{x \in Q_{1}} f_{1}(x) \cap \arg \min _{x \in Q_{1}} f_{2}(x) \cap \cdots \cap \arg \min _{x \in Q_{l}} f_{l}(x)$

and

$$
A_{1} \bar{x} \in \arg \min _{w \in Q_{2}} g_{1}(w), \quad A_{2} \bar{x} \in \arg \min _{w \in Q_{2}} g_{2}(w), \quad \ldots, \quad A_{l} \bar{x} \in \arg \min _{w \in Q_{2}} g_{l}(w),
$$

where $m \in \mathbb{N}$ and $l \in \mathbb{N}$.

Let $\Omega_{3}$ denote the solution set of the problem (MSSVIP-3).

Theorem 4.3 In Theorem 4.2, we assume further that $V_{1}$ and $V_{2}$ are nonempty open convex sets in $\mathcal{H}_{1}$ and $\mathcal{H}_{2}$, respectively, $Q_{1} \subset V_{1}, Q_{2} \subset V_{2}$. For each $i \in \mathbb{N}$, let $f_{i}: V_{1} \rightarrow \mathcal{R}$ and $g_{i}: V_{2} \rightarrow \mathcal{R}$ be convex Gâteaux differential functions. For each $i \in \mathbb{N}$, suppose that $B_{i}$ and $L_{i}$ are strongly monotone and Lipschitz continuous on $Q_{1}$ and $Q_{2}$, respectively, and $B_{i}$ and $L_{i}$ be the Gâteaux derivatives of $f_{i}$ and $g_{i}$, respectively. Then the sequence $\left\{x_{n}\right\}_{n \in \mathbb{N}}$ defined in (4.1) converges strongly to some $\bar{x} \in \Omega_{3}$.

Proof Since for each $i \in \mathbb{N}, B_{i}$ and $L_{i}$ are Lipschitz and strongly monotone, it is easy to see that $B_{i}$ and $L_{i}$ are inverse strongly monotone. By Theorem 4.2, the sequence $\left\{x_{n}\right\}_{n \in \mathbb{N}}$ defined in (4.1) converges strongly to some $\bar{x} \in \Omega_{2}$. Therefore for each $i=1,2, \ldots, m, j=$ $1,2, \ldots, l, \bar{x} \in B_{i}^{-1} 0, A_{j} \bar{x} \in L_{j}^{-1} 0$. Since for each $i \in \mathbb{N}, f_{i}: V_{1} \rightarrow \mathcal{R}$ and $g_{i}: V_{2} \rightarrow \mathcal{R}$ are convex 
Gâteaux differential functions with Gâteaux derivatives $B_{i}$ and $L_{i}$, respectively, we obtain

$$
\begin{aligned}
0 & =\left\langle B_{i} \bar{x}, y-\bar{x}\right\rangle=\lim _{t \rightarrow 0} \frac{f_{i}(\bar{x}+t(y-\bar{x}))-f_{i}(\bar{x})}{t} \\
& =\lim _{t \rightarrow 0} \frac{f_{i}((1-t) \bar{x}+t y)-f_{i}(\bar{x})}{t} \leq \lim _{t \rightarrow 0} \frac{(1-t) f_{i}(\bar{x})+t f_{i}(y)-f_{i}(\bar{x})}{t}=f_{i}(y)-f_{i}(\bar{x})
\end{aligned}
$$

for all $y \in V_{1}$.

Then, for each $i=1,2, \ldots, m, f_{i}(y) \geq f_{i}(\bar{x})$ for all $y \in Q_{1}$ and $\bar{x} \in \arg \min _{y \in Q_{1}} f_{i}(y)$.

Similarly, for each $j=1,2, \ldots, l, g_{j}(w) \geq g_{j}\left(A_{j} \bar{x}\right)$ for all $w \in Q_{2}$ and $A_{j} \bar{x} \in \arg \min _{w \in Q_{2}} g_{j}(w)$.

This shows that $\bar{x} \in \Omega_{3}$.

Let $f$ be a proper lower semicontinuous convex function of $H_{1}$ into $(-\infty, \infty)$. The subdifferential $\partial f$ of $f$ is defined as follows:

$$
\partial f(x)=\left\{z \in H_{1}: f(x)+\langle z, y-x\rangle \leq f(y), \forall y \in H_{1}\right\}
$$

for all $x \in H_{1}$. From Rockafellar [25], we know that $\partial f$ is a maximal monotone operator. Let $C$ be a nonempty closed convex subset of a real Hilbert space $H_{1}$, and $i_{C}$ be the indicator function of $C$, i.e.

$$
i_{C} x= \begin{cases}0 & \text { if } x \in C, \\ \infty & \text { if } x \notin C .\end{cases}
$$

Then $i_{C}$ is a proper lower semicontinuous convex function on $H$, and the subdifferential $\partial i_{C}$ of $i_{C}$ is a maximal monotone operator. We define the resolvent $J_{\lambda}^{\partial i_{C}} x=\left(I+\lambda \partial i_{C}\right)^{-1} x$ for all $x \in H$. We have $J_{\lambda}^{\partial i_{C}}=P_{C}$.

For each $i \in \mathbb{N}$, and $j \in \mathbb{N}$, let $C_{1}, C_{2}, \ldots, C_{m}$ be nonempty closed convex subsets of $\mathcal{H}_{1}$ and $D_{1}, D_{2}, \ldots, D_{l}$ be nonempty closed convex subsets of $\mathcal{H}_{2}$.

In the following theorem, we study the following multiple sets split feasibility problems (MSSVIP-4):

Find $\bar{x} \in \mathcal{H}_{1}$ such that $\bar{x} \in C_{1} \cap C_{2} \cap \cdots \cap C_{m}$ and $A_{1} \bar{x} \in D_{1}, A_{2} \bar{x} \in D_{2}, \ldots, A_{l} \bar{x} \in D_{l}$, where $m \in \mathbb{N}, l \in \mathbb{N}$.

Let $\Omega_{4}$ denote the solution set of the problem (MSSVIP-4).

Theorem 4.4 For each $i \in \mathbb{N}$, and $j \in \mathbb{N}$, let $C_{1}, C_{2}, \ldots, C_{m}$ be the nonempty closed convex subsets of $\mathcal{H}_{1}$ and $D_{1}, D_{2}, \ldots, D_{l}$ be nonempty closed convex subsets of $\mathcal{H}_{2}$. Let $T_{1}: Q_{1} \rightarrow Q_{1}$ be a mapping defined by

$$
T_{1}=P_{C_{1}} P_{C_{2}}, \ldots, P_{C_{m}}
$$

and $T_{2}: Q_{1} \rightarrow Q_{1}$ a mapping defined by

$$
T_{2}=\left(I-\sigma_{1} A_{1}^{*}\left(I_{2}-P_{D_{1}}\right) A_{1}\right)\left(I-\sigma_{2} A_{2}^{*}\left(I_{2}-P_{D_{2}}\right) A_{2}\right) \cdots\left(I-\sigma_{l} A_{l}^{*}\left(I_{2}-P_{D_{l}}\right) A_{l}\right),
$$

where $m \in \mathbb{N}$, and $l \in \mathbb{N}$. 
Suppose that $\Omega_{4} \neq \emptyset$.

Let $\left\{\alpha_{n}\right\}_{n \in \mathbb{N}},\left\{\beta_{n, 1}\right\}_{n \in \mathbb{N}},\left\{\beta_{n, 2}\right\}_{n \in \mathbb{N}},\left\{\beta_{n, 3}\right\}_{n \in \mathbb{N}}$ be sequences in $[0,1]$ satisfying the following control conditions:

(a) $\lim _{n \rightarrow \infty} \alpha_{n}=0$;

(b) $\sum_{n=1}^{\infty} \alpha_{n}=\infty$;

(c) $\beta_{n, 1}+\beta_{n, 2}+\beta_{n, 3}=1, \forall n \in \mathbb{N}$;

(d) $\liminf _{n \rightarrow \infty} \beta_{n, j} \beta_{n, 3}>0, j=1,2$;

(e) for each $i \in \mathbb{N}, 0<\sigma_{i}<\frac{1}{R_{i}}$.

Let $\left\{x_{n}\right\}_{n \in \mathbb{N}}$ be a sequence generated by

$$
\left\{\begin{array}{l}
x_{1} \in C \quad \text { chosen arbitrarily, } \\
y_{n}=\beta_{n, 1} T_{1} x_{n}+\beta_{n, 2} T_{2} x_{n}+\beta_{n, 3} x_{n}, \\
x_{n+1}=\alpha_{n} z+\left(1-\alpha_{n}\right) y_{n} .
\end{array}\right.
$$

Then the sequence $\left\{x_{n}\right\}_{n \in \mathbb{N}}$ defined in (4.3) converges strongly to some $u_{0} \in \Omega_{4}$, where

$$
u_{0}=\arg \min _{u \in \Omega_{4}}\|u-z\|
$$

Proof Let $G_{i}=\partial i_{C_{i}}, B_{i}=0, M_{j}=\partial i_{D_{j}}, L_{i}=0$ in Theorem 4.1. Then Theorem 4.4 follows from Theorem 4.1.

Example 4.1 Let $T: \mathbb{R} \rightarrow[0,2]$ be defined by

$$
T x= \begin{cases}0 & \text { if } x \in(-\infty, 2) \\ 1 & \text { if } x \in[2, \infty)\end{cases}
$$

Then, $T$ is a nonspreading mapping. Indeed, for any $x \in(-\infty, 2)$ and $y \in[2, \infty)$, we have $T x=0$ and $T y=1$. Observe now that

$$
\begin{aligned}
2|T x-T y|^{2} & =2|0-1|^{2} \\
& \leq|x-1|^{2}+|y-0|^{2} \\
& =|x-T y|^{2}+|y-T x|^{2} .
\end{aligned}
$$

Therefore, $T$ satisfies condition $E_{2}$ with $A(T)=(-\infty, 0]$. Let $z=1, \alpha_{n}=\frac{1}{n}, x_{1}=2$, then $T x_{1}=1, x_{2}=\frac{1}{2}, \ldots, x_{n+1}=\frac{1}{n}$. We see that the sequence $x_{n}$ converges strongly to $0 \in A(T)$.

The authors declare that they have no competing interests.

\section{Authors' contributions}

All authors contributed equally to the writing of this paper. All authors read and approved the final manuscript.

\section{Author details}

'Department of Mathematics, Yasouj University, Yasouj, 75918, Iran. ²Department of Mathematics, National Changhua University of Education, Changhua, 50058, Taiwan. 


\section{References}

1. Takahashi, W, Takeuchi, Y: Nonlinear ergodic theorem without convexity for generalized hybrid mappings in a Hilbert space. J. Nonlinear Convex Anal. 12, 399-406 (2011)

2. Halpern, B: Fixed points of nonexpanding mappings. Bull. Am. Math. Soc. 73, 957-961 (1967)

3. Akashi, S, Takahashi, W: Strong convergence theorem for nonexpansive mappings on star-shaped sets in Hilbert spaces. Appl. Math. Comput. 219(4), 2035-2040 (2012)

4. García-Falset, J, Llorens-Fuster, E, Suzuki, T: Fixed point theory for a class of generalized nonexpansive mappings. J. Math. Anal. Appl. 375, 185-195 (2011)

5. Censor, Y, Elfving, T: A multiprojection algorithm using Bregman projection in a product space. Numer. Algorithms 8 , 221-239 (1994)

6. Henry, S: Image Recovery Theory and Applications. Academic Press, Orlando (1987)

7. Combettes, PL: The convex feasible problem in image recovery. In: Hawkes, P (ed.) Advanced in Image and Electron Physics, vol. 95, pp. 155-270. Academic Press, New York (1996)

8. Byrne, C: Iterative oblique projection onto convex sets and the split feasibility problem. Inverse Probl. 18, 441-453 (2002)

9. Byrne, C: A unified treatment of some iterative algorithms in signal processing and image reconstruction. Inverse Probl. 20, 103-120 (2004)

10. Lopez, G, Martinez-Marquez, V, Wang, F, Xu, HK: Solving the split feasibility problem without prior knowledge of matrix. Inverse Probl. 28, 085004 (2012)

11. Censor, Y, Bortfeld, T, Martin, B, Trofimov, A: A unified approach for inversion problems in intensity-modulated radiation therapy. Phys. Med. Biol. 51, 2353-2365 (2003)

12. Kohsaka, F, Takahashi, W: Fixed point theorems for a class of nonlinear mappings relate to maximal monotone operators in Banach spaces. Arch. Math. 91, 166-177 (2008)

13. Suzuki, T: Fixed point theorems and convergence theorems for some generalized mappings. J. Math. Anal. Appl. 340, 1088-1095 (2008)

14. Takahashi, W: Nonlinear Functional Analysis. Fixed Point Theory and Its Applications. Yokahama Publishers, Yokahama (2000)

15. Geobel, K, Kirk, WA: Topics on metric fixed-point theory. In: Cambridge Studies in Advanced Mathematics, vol. 28 Cambridge University Press, Cambridge (1990)

16. Xu, HK, Kim, TH: Convergence of hybrid steepest-descent methods for variational inequalities. J. Optim. Theory Appl. 119(1), 185-201 (2003)

17. Aoyama, K, Kimura, Y, Takahashi, W, Toyoda, M: Approximation of common fixed points of a countable family of nonexpansive mappings in a Banach space. Nonlinear Anal. 67, 2350-2360 (2007)

18. Maing, PE: Strong convergence of projected subgradient methods for nonsmooth and nonstrictly convex minimization. Set-Valued Anal. 16, 899-912 (2008)

19. Cho, YJ, Zhou, HY, Guo, G: Weak and strong convergence theorems for three-step iterations with errors for asymptotically nonexpansive mappings. Comput. Math. Appl. 47, 707-717 (2004)

20. Chang, SS, Kim, JK, Wang, XR: Modified block iterative algorithm for solving convex feasibility problems in Banach spaces. J. Inequal. Appl. 2010, Article ID 869684 (2010). doi:10.1155/2010/86968

21. Combettes, PL: Solving monotone inclusions via compositions of nonexpansive averaged operators. Optimization 53(5-6), 475-504 (2004)

22. $\mathrm{Xu}, \mathrm{HK}$ : Iterative methods for the split feasibility problem in infinite-dimensional Hilbert spaces. Inverse Probl. 26 $105018(2010)$

23. Yu, ZT, Lin, LJ, Chuang, CS: Mathematical programming with multiple sets split monotone variational inclusion constraints. Fixed Point Theory Appl. 2014, Article ID 20 (2014)

24. Moudafi, A: Split monotone variational inclusions. J. Optim. Theory Appl. 150, 275-283 (2011)

25. Rockafellar, RT: Monotone operators associated with saddle functions and minimax problems. In: Browder, FE (ed.) Nonlinear Functional Analysis. Part I. Proceedings of Symposia in Pure Math., vol. 18, pp. 241-250. Am. Math. Soc., Providence (1970)

10.1186/1687-1812-2014-72

Cite this article as: Naraghirad and Lin: Strong convergence theorems for generalized nonexpansive mappings on star-shaped set with applications. Fixed Point Theory and Applications 2014, 2014:72

\section{Submit your manuscript to a SpringerOpen ${ }^{\circ}$ journal and benefit from:}

- Convenient online submission

- Rigorous peer review

Immediate publication on acceptance

- Open access: articles freely available online

- High visibility within the field

- Retaining the copyright to your article 